This is a post-peer-review, pre-copyedit version of an article published in Psychological Research.

The final authenticated version is available online at: https://doi.org/10.1007/s00426-018-1031-6 


\section{Deep, Effortless Concentration: Re-examining the Flow Concept and exploring relations}

with Inattention, Absorption, and Personality

Jeremy Marty-Dugas \& Daniel Smilek

Department of Psychology

University of Waterloo

200 University Ave. West, Waterloo, ON, N2L 3G1, Canada

Corresponding Author: Jeremy Marty-Dugas

Department of Psychology, University of Waterloo

200 University Ave. West, Waterloo, ON, N2L 3G1

Email: jmartydu@uwaterloo.ca

Telephone: 519-888-4567 x36819

Ackowledgements We wish to thank Dr. Erik Woody for his helpful and insightful comments on an earlier version of this paper. As well, we wish to thank three anonymous reviewers for their insightful comments and suggestions on our manuscript. This research was supported by a Natural Science and Engineering Research Council of Canada (NSERC) discovery grant awarded to Daniel Smilek, a Queen Elizabeth II Graduate Scholarship in Science and Technology awarded to Jeremy Marty-Dugas. 


\begin{abstract}
Conceptualizing the construct of flow in terms of 'deep and effortless concentration', we developed two measurement scales designed to index individual differences in flow during 'internal' tasks, such as thinking (Deep Effortless Concentration: Internal - DECI) and during 'external' tasks, such as while playing a sport (Deep Effortless Concentration: External - DECE). These scales were highly correlated, indicating that individuals prone to experiencing flow in external contexts are also prone to experience flow in internal contexts. Nonetheless, a measurement model construing internal and external flow as related, but separate, constructs was found to fit the data significantly better than a model where they were construed as a single construct. We then explored associations between flow and various forms of everyday inattention. In addition, we explored the relation between flow and the Tellegen Absorption Scale (TAS), an index of absorption, as well as the Big Five personality traits. Amongst other things, we found that flow was negatively related to inattention, indicating that people who experience flow more frequently may experience relatively less inattention in everyday contexts.
\end{abstract}

Keywords: Flow, Inattention, Sustained Attention, Focus, Effortless, Concentration, Big Five 
Deep, Effortless Concentration: Re-examining the Flow Concept and exploring relations with Inattention, Absorption, and Personality

The psychological experience of flow is characterized by the subjective experience of full engagement in what one is doing, to the point that attending to task-relevant stimuli seems effortless. Csikszentmihalyi (1975/1990) pioneered research on the flow experience, by observing the behaviour of artists during the creative process. The artists ignored hunger, sleep, fatigue, and distractions while remaining completely focused on the creation of their paintings. Since then, research on flow has been studied in multiple domains, most notably during sports (Catley \& Duda, 1997; Crust \& Swann, 2013; Jackson, Kimiecik, Ford, \& Marsh, 1998; Jackson \& Marsh, 1996; Jackson, Thomas, Marsh, \& Smethurst, 2001; Stavrou, Zervas, Karteroliotis, \& Jackson, 2007; Swann, Keegan, Piggot, \& Crust, 2012). In the present paper we build on the burgeoning flow literature by: 1) advocating for the conceptualization of flow in terms of deep and effortless concentration; 2) reporting on the development of two new self-report scales that measure individual differences in flow (defined as deep, effortless concentration) in both internal (e.g., thinking) and external (e.g., completing a physical task) contexts, and examining the relation between flow experiences in these two contexts; 3) examining the relations between individual differences in internal and external flow and everyday forms of inattention (e.g., mind-wandering); 4) assessing whether our new measures of flow are unique from the gold-standard measure of absorption, a construct that is conceptually similar (if not identical) to flow; and finally 5) examining the relations among internal and external flow and the Big Five personality traits. In what follows we briefly discuss the prior literature that pertains to each of the foregoing issues. 


\section{Construing Flow as Deep, Effortless Concentration}

In considering the conceptual aspects of flow, we believe it is important to also consider the way in which flow experiences have typically been measured. This is partly because measures of flow can reveal implicit or tacit definitions of the flow concept. Additionally, there is the possibility that the development of the flow concept may have even been influenced by the measures that were used to index the experience.

In the extant literature, flow is typically characterized as a broad, global construct that incorporates nine facets (Jackson \& Marsh, 1996; Jackson et al., 1998; Nakamura \& Csikszentmihalyi, 2002; Swann et al, 2012). These facets include 1) a balance between the individual's skill and the challenge afforded by the situation (skill-challenge balance), 2) clear goals, 3) immediate and unambiguous feedback, 4) focused concentration, 5) a merging of action and awareness, 6) loss of self-consciousness, 7) a heightened sense of control, 8) time distortion, and 9) experiencing the activity as intrinsically rewarding (Csikszentmihalyi, 1988; Jackson \& Eklund, 2002; Jackson \& Marsh, 1996; Jackson et al., 2001; Macbeth, 1988; Nakamura \& Csikszentmihalyi, 2002). In many cases these facets are considered to play equal roles in flow experiences, and this is directly reflected in the way in which flow is commonly measured. In practice, flow is usually measured by collecting participants' ratings on the facets of flow and summing them to create a global score (e.g. Aherne, Moran, \& Lonsdale, 2011; Ullén et al., 2012). This method of summing the facets implies that each one contributes equally to the flow experience. Problematic for the view that flow is an equal combination of the nine facets are 1) findings from qualitative studies showing that some facets of flow are more commonly reported as characteristic of flow states than others, with facets such as time distortion occurring quite rarely (Swann et al, 2012), and 2) the finding that some of the nine facets of flow only load weakly onto a global flow factor (Jackson \& Eklund, 
2002; Jackson \& Marsh, 1996). Some investigators suggest that a better way to construe flow is as 'more than the sum of its parts' (Csikszentmihalyi \& Csikszentmihalyi, 1988; Jackson \& Eklund, 2002), which would seem to imply that flow is some sort of emergent property of the nine facets. However, in practice, the nine facets are simply summed (or simply evaluated individually), and the conceptualization of flow as being 'more than the sum of its parts' continues to elude empirical measurement and perhaps even conceptual clarity.

In contrast to the common view that flow is comprised of a combination of nine facets, we wish to advocate for the position that the experience of flow is best characterized by a single core concept, namely, the subjective experience of "deep, effortless concentration". By the term "deep" we mean the general experience of being fully engaged or completely focused on whatever one is doing; and by the term 'effortless' we meant the act of sustaining one's attention without 'forcing it' or experiencing strain while doing so. Indeed, Nakamura and Csikszentmihalyi (2002, p. 92) note: "The phenomenology of flow reflects attentional process. Intense concentration, perhaps the defining quality offlow, is just another way of saying that attention is wholly invested in the present exchange." (italics added). Csikszentmihalyi and Nakamura (2010, p. 182) make this point even more explicitly, stating: "...we realize that the definition of this signature quality of the flow state can be made more precise... it is specifically the experience of complete but also effortless attention that is associated with being in the enjoyable state of flow." Qualitative studies of flow are consistent with this conceptualization, with the findings of a recent meta-analysis showing that of 114 elite athletes who were interviewed, over $80 \%$ described concentration on the task as part of their experience - more than any other flow facet (Swann et al, 2012). 
Assuming that "deep, effortless concentration" defines flow, how do the other aforementioned facets relate to this conceptualization of flow? One way to construe the other aforementioned facets (those aside from deep, effortless concentration) is to consider them to be either the precursors or the consequences of flow. The precursor facets would be those facets that, if modulated, make flow experiences more or less likely, or vary the depth of flow (e.g. skill-challenge balance, clear goals), while the consequences of flow would be those facets that change as a result of experiencing deep, effortless concentration (e.g. time distortion, loss of self-consciousness, action-awareness merging). This general conceptualization is in line with suggestions made by other researchers, who proposed that flow facets can be arranged into 'conditions' and 'outcomes' (e.g., Hamari \& Koivisto, 2014; see also Landhäußer \& Keller, 2012). It is worth noting, however, that there is not always agreement about which particular facets should be construed as conditions or outcomes (Hamari \& Koivisto, 2014). Nevertheless, these considerations may have important implications for the measurement of flow, specifically, the common practice of summing responses across multiple facets of flow. When summing all of the facets, deep and effortless concentration is given no more weight than the other facets, which becomes problematic if one assumes flow is deep, effortless concentration.

Re-conceptualizing flow as deep, effortless concentration also impacts the interpretation of prior findings. Take for example, a study conducted by Aherne, et al., (2011) in which some athletes completed six weeks of mindfulness training (the mindfulness training group) while others did not (the control group). The flow measure (i.e., the Flow State Scale-2; Jackson \& Eklund, 2002) was completed by both groups before and after the six-week period. Aherne et al., (2011) found that for the mindfulness training group, overall flow scores were higher after training than before the training; in contrast, the control group showed no improvement. The increase in overall 
flow scores associated with mindfulness training was driven by an increase in the facets of clear goals and the sense of control. Critically, while these findings are certainly straightforward and interesting, the point we want to make here is that their interpretation could vary substantially depending on how flow is conceptualized. If flow is conceptualized as the summation of multiple facets, then Aherne et al.'s, (2011) findings could be legitimately taken as evidence that mindfulness training increases flow. However, if flow is conceptualized using the more specific definition of deep, effortless concentration, then the results do not provide any direct evidence that mindfulness training increases flow. This is because, clearly, participants in the study did not experience any measurable change in what some would consider to be the defining feature of the flow experience, namely, deep, effortless concentration.

To make a similar point, consider several recent studies of flow that involved experimental manipulations of skill-challenge balance (Ulrich, Keller, Hoenig, Waller, \& Grön 2014; Ulrich, Keller, \& Grön, 2016). In these studies, an adaptive algorithm was used to present participants with math problems that were either matched to their skill level (the optimal balance condition), below their skill level (underload condition), or above their skill level (overload condition) ${ }^{1}$. Flow was measured using a "flow index", which assessed 1) whether participants felt their skills were matched to the challenge, 2) whether they felt thrilled, and 3) whether participants would "love" to solve the math problems again. ${ }^{2}$ The results showed that the items of this index were endorsed to a greater degree in the optimal balance condition, compared to the underload and overload conditions. Again, the interpretation of these findings depends on the way flow is conceptualized. If

\footnotetext{
${ }^{1}$ These conditions are often referred to as the 'flow', 'boredom', and 'anxiety' conditions, respectively, but we find the terms optimal balance, underload, and overload are less ambiguous about the level of skill-challenge balance ${ }^{2}$ Of the original nine items, three were selected for the flow index. These were "I would love to solve math calculations of that kind again" "I was thrilled" and "Task demands were well matched to my ability". The same items were also used in the 2016 paper.
} 
it is assumed that flow is the sum of the facets measured (as was done by the authors), it can be concluded that the optimal balance condition produced greater flow than each of the other two conditions. As an aside, with such a conceptualization (which includes skill-challenge balance as a fact of flow), it might not be readily apparent that the same variable (skill-challenge balance) is being both manipulated and measured. However, if flow is re-conceptualized in terms of deep, effortless concentration, then the findings do not unequivocally show that varying skill-challenge balance influences flow. This is precisely because none of the items in the flow index directly measured deep, effortless concentration.

Defining flow in terms of deep, effortless concentration has several important advantages. First, it makes the flow concept more specific (focusing on one facet rather than the combination of many), which has the added benefit of allowing for a more targeted measurement of the concept. Second, it allows for a clearer distinction of the flow concept from the precursors and consequences of the experience. This also has measurement implications. For example, defining and measuring flow as deep, effortless concentration would likely prevent one from manipulating skill-challenge balance (as a cause) and then also measuring skill-challenge balance as part of the flow concept. Third, defining flow in terms of deep, effortless concentration allows for flow to be assessed even in moments when some of the facets previously associated with flow do not seem to apply. For instance, as we will discuss shortly, flow, defined as deep, effortless concentration, can be measured during both external tasks (e.g., sports) and internal tasks (e.g., thinking). In contrast, measuring flow during internal tasks is awkward, if not impossible, under the multi-faceted view of flow, particularly when action and awareness merging is thought to be one of the key facets. 


\section{Towards New Measures of Flow}

With the adoption of a more targeted definition of the flow concept, it is clear that what is needed is a more specific measure of flow; one that is more in line with the conceptualization of flow as deep, effortless concentration. Fortunately, just such a measure was created by Csikszentmihalyi and Nakamura (2010) in their re-analysis of historical experience sampling data. The data included responses from high school students who had been probed using pagers to report on a number of their experiences, including their levels of concentration ("How well were you concentrating?"), and effort ("Was it hard to concentrate?"). Those instances in which participants reported the co-occurrence of a high level of concentration and a low level of effort were considered effortless attention (i.e. experiences of flow). Interestingly, Csikszentmihalyi and Nakamura (2010) found that flow was more likely to occur when the students had freely chosen their own task, rather than when a task was mandatory. This is reminiscent of findings showing that fatigue seems to occur disproportionately during "have to", as opposed to "want to" tasks (Hockey, 2013; but see Csikzsentmihalyi \& LeFevre, 1989). A recent study (Harmat, de Manzano, Theorell, Högman, Fischer, \& Ullén, 2015) used similar questions to measure flow while participants played Tetris at three different levels of difficulty (i.e. different levels of skill-challenge balance). It was found that high levels of concentration and low levels of effort co-occurred (i.e., the combination indicative of flow) most frequently when the challenge of the game was matched to the skill level of participants (e.g. an optimal balance condition). Studies such as these (i.e. those measuring deep, effortless concentration) allow one to draw more precise conclusions about flow because they measure flow with greater specificity. Building on the forgoing work, one primary goal of the present study was to create a measure of flow that would specifically assess deep, effortless concentration at the trait (individual-difference) level. 


\section{Internal and External Flow}

In empirical investigations of flow, one context that has received relatively little attention is the experience of flow during internal thought (here referred to as 'internal flow'). As noted by Nakamura and Csikszentmihalyi (2002, p. 102): "Relatively little research has addressed the experience of flow when attention is trained on internal sources of information (e.g. in psychotherapy, life-planning, life-review, and other forms existential reflection; fantasy; spiritual experience)." One notable exception is a study by Csikszentmihalyi and LeFevre (1989), in which people reported they experienced flow while daydreaming.

Perhaps one reason for the paucity of studies examining internal flow is that some of the nine facets often believed to constitute the flow experience focus almost exclusively on external tasks and they seem to apply less clearly to internal thoughts. For example, two such facets are 'action-awareness merging' and 'skill-challenge balance', which are both most easily understood with reference to an external task. If these facets were to be construed as integral parts of the flow experience, as indeed they have been in the past, then one might even conclude that flow cannot occur during internal tasks, such as daydreaming. This apparent bias towards conceptualizing flow in the context of external tasks likely stems from the fact that historically, flow has been assessed primarily in the context of people engaging in external tasks, such as sports (Catley \& Duda, 1997; Crust \& Swann, 2013; Jackson \& Marsh, 1996; Jackson et al., 1998; Jackson et al., 2001; Jackson \& Eklund, 2002; Stavrou et al., 2007; Swann et al., 2012; Swann, 2016). As theory developed based on these observations, a reference to external tasks seems to have become integral to the conceptual development and measurement of flow.

As we noted earlier, one advantage of defining flow specifically in terms of the core characteristic of deep, effortless concentration is that it has the added benefit of breaking free from the 
current focus on external tasks. This is because the core concept of deep, effortless concentration can apply equally to both external and internal contexts. The other facets associated with flow (i.e., the precursors and consequences) are then free to vary across internal and external contexts without requiring a different definition or different measures of flow across contexts. Thus, using the more specific definition of flow (as deep, effortless concentration) allows for the examination of the flow state in a broader range of circumstances.

Based on the foregoing considerations, one of the main goals of the present study was to develop a measure of flow (defined as deep, effortless concentration) to index the experience flow during internal contexts. A secondary goal was to compare individual differences in the propensity to experience flow in internal tasks (internal flow) with the propensity to experience flow during external tasks (external flow). Accordingly we created two matching subjective report scales, for assessing flow during both internal and external tasks.

\section{Flow and Everyday Inattention}

Given that flow can be characterized as the experience of peak attentional focus, it is not surprising that there have been attempts to examine the relation between flow and sustained attention ability. For instance, Ullén et al., (2012) examined the relation between scores on the Swedish Flow Proneness Questionnaire (SFPQ), which they used as a trait measure of flow, and scores on the Raven's Progressive Matrices (Raven, 1962; 1965), which they treated as an index of sustained attention. They found no correlation between scores on the SFPQ and performance on the Raven's Matrices and thus concluded that there is no relation between flow and sustained attention performance. However, a weakness of this study is that sustained attention was assessed using the Raven's Matrices, a measure that was not designed to specifically index sustained attention ability. In a more recent report, Ullén, Harmat, Theorell, and Madison (2016) found no relation between 
flow proneness and attention performance as indexed by a set of chronometric tasks, such as pressing the spacebar as quickly as possible after a target stimulus, responding in time with a metronome, and maintaining the rhythmic response after the metronome could no longer be heard. However, while performance on the tasks used in this study showed no relation to the measure of flow, it is not clear that these tasks are good measures of attention performance per se. Notwithstanding the problematic measurements of sustained attention, the foregoing results have been taken as support for the conclusion that effortless attention (experiences that include, but are not limited to, flow) and sustained attention are supported by different neural mechanisms (Ullén, de Manzano, Theorell, \& Harmat, 2010; Ullén et al., 2012; Ullén et al., 2016). This conclusion is inconsistent with the intuition that a greater ability to sustain attention should relate to a higher likelihood of experiencing flow, as seems to be implied by flow theory (Csikszentmihalyi, 1978; Nakamura \& Csikzentmihalyi, 2002)

In contrast to the foregoing findings, some researchers (Cermakova, Moneta, \& Spada, 2010; Moore, 2013) have reported a positive correlation between dispositional flow and sustained attention abilities. For example, in a study assessing the association between academic outcomes and different kinds of motivation, Cermakova, Moneta, and Spada (2010) also examined the relation between dispositional flow, as indexed by the Dispositional Flow Scale-2 (DFS-2; Jackson \& Eklund, 2002) $)^{3}$, and attention control, as indexed by the Attentional Control Scale (ACS; Derryberry \& Reed, 2002). Scores on these measures were significantly positively correlated $(\mathrm{r}=.55)$, suggesting that people with greater control over their attention also experience relatively more episodes of flow. As another example, Moore (2013) examined the relation between mindfulness, as indexed by the Cognitive and Affective Mindfulness Scale-Revised (CAMS-R: Feldman,

\footnotetext{
${ }^{3}$ for example items from an earlier version of the DFS-2, see Jackson \& Marsh, 1996
} 
Hayes, Kumar, Greeson, \& Laurenceau, 2007), and dispositional flow as indexed by DFS-2. Mindfulness (of which a key component is sustaining attention; see Bishop et al., 2004) and flow were found to have a significant positive correlation $(r=.50)$, again suggesting that better sustained attention abilities may be conducive to flow experiences.

When taken together, the foregoing research reveals that the relation between trait flow and sustained attention ability is unclear as the available studies seem to point to conflicting conclusions. As such, a major goal of the present study was to better understand this relation. A unique aspect of the current investigation is that we examine the relation between flow, defined as deep effortless concentration, and everyday forms of inattention, such as absent-mindedness, attentionrelated errors (e.g. putting the milk in the pantry instead of the fridge), and mind-wandering.

\section{Flow and Absorption}

Flow is often defined as a peak attentional experience, whereby the individual experiences a state of complete and almost effortless focus. However, a very similar description is used to define the concept of absorption. In their seminal paper, Tellegen and Atkinson (1974) describe absorption as "a disposition for having episodes of 'total' attention that fully engage one's representational...resources" as well as an "imperviousness to distracting events". In some cases, absorption is even used as a way of defining the flow experience (Crust \& Swann, 2013; Csikszentmihalyi, 1990; Csikszentmihalyi \& Nakamura, 2002; Harari, 2008; Jackson \& Marsh, 1996; Martin \& Jackson, 2008; Peifer, Schulz, Schächinger, Baumann, \& Antoni, 2014; Ullén et al., 2010, Wright, Sadlo \& Stew, 2006; Wright, Sadlo \& Stew, 2007). For example Jackson et al., (2001, p.18) state: "It [flow] is a state of concentration so focused that it amounts to absolute absorption in an activity." In addition, in some studies, items asking participants about their level of absorption during an experimental task have even been included in indices of flow (Engeser \& Rheinberg, 
2008; Peifer et al, 2014). However, despite this high degree of conceptual similarity/overlap between flow and absorption, the literature on flow appears to have progressed more or less separately from the literature focusing on absorption.

One possible reason for the lack of integration between the flow and absorption literatures has to do with the nuances of the measures used to index the two constructs. In the absorption literature, perhaps the most prominent (i.e., gold standard) measure of absorption is the Tellegen Absorption Scale (TAS; Tellegen \& Atkinson, 1974), which indexes absorption at the trait level. A consideration of the items of the $\mathrm{TAS}^{4}$ reveals that the scale might not simply index absorption in general, but rather that it might index a sort of over-engagement, which could be maladaptive, or even dissociative. In fact, the TAS is positively related to the Dissociative Experiences Scale (DES), which indexes abnormal dissociative experiences (Nadon, Hoyt, Register \& Kihlstrom, 1991; Smyser \& Baron, 1993). Interestingly, procrastination, an avoidance based mood-regulation strategy, has been found to be positively related to the TAS as well (Sirois, 2014). Thus, the TAS does not match the overall character of flow measures, which seem to focus more on the experience of one's goals, actions, and values becoming aligned and leading to a feeling of ordered consciousness (Jackson \& Marsh, 1996; Wright et al., 2007).

The foregoing considerations beg the question: How might indices of flow and indices of absorption be related at a measurement level? On the one hand, one might expect a positive correlation between flow and absorption measures because of the similarity at the cores of the two constructs (i.e. complete and effortless focus). On the other hand, as noted above, there are important nuanced differences in the measures, which could lead to the absence of a correlation. Perhaps the most likely outcome, which balances the foregoing considerations, is that the measures

\footnotetext{
${ }^{4}$ See Tellegen \& Atkinson, 1974 for some example items
} 
would be modestly positively correlated. Regardless, we endeavoured to check (and perhaps disconfirm) the possibility that our newly created scales simply recapitulated the gold standard measure of absorption (i.e., the TAS). To this end we examined the relation between the TAS and each of our internal and external flow scales.

\section{Flow and Personality}

Since its inception, it has been recognized that while flow may be an elusive experience, there may be some individuals who experience flow more often than others (Csikszentmihalyi, 1975/2000). The term "autotelic personality" was introduced to refer to those who experience flow most frequently. The autotelic personality is typically measured using the Flow Questionnaire (e.g. Asakawa, 2010; Csikszentmihalyi 1975/2000; Han 1988), which provides participants with a description of the flow experience, and asks how frequently, and during which activities, they have had such an experience. Thus, at the most basic level, the autotelic personality has been defined as the propensity to experience flow (Asakawa, 2010). Recently, some researchers have started investigating 'flow proneness', rather than the autotelic personality per se. The distinction, though, is somewhat blurred, given that the autotelic personality seems to be largely defined by the frequency of flow experience. The main difference appears to be the use of measurement tools. Flow proneness is usually indexed using scales such as the SFPQ (Ullén et al., 2012; 2016), or the DFS2 (Jackson \& Eklund, 2002; Ross \& Keiser, 2014). These measures assess how often individuals experience specific facts of flow ${ }^{5}$ (which are then summed to a create global flow score, or assessed individually). In contrast, the Flow Questionnaire, which is used to index the 'autotelic personality' provides a holistic description of the flow experience and then asks participants how often they have had such experiences.

\footnotetext{
${ }^{5}$ SFPQ assesses seven facets using one item each (with three subscales to measure flow in different contexts), while the DFS-2 assess nine facets using four items per facet).
} 
The autotelic personality has been conceptually associated with, and even characterized by, several other personality traits (Nakamura \& Csikszentmihalyi, 2002). For example, curiosity, persistence, and low self-centeredness are thought to allow a person to be motivated by the intrinsic qualities of an activity or experience and to enter flow states more easily (Nakamura \& Csikszentmihalyi, 2002). Other qualities associated with the autotelic personality include greater well-being, lower trait anxiety, and a greater tendency to use adaptive coping strategies (Asakawa, 2010). These qualities of the autotelic personality bear some similarity to several of the Big Five personality traits (which include Openness, Conscientiousness, Extraversion, Agreeableness, and Neuroticism; see, John, Naumann, \& Soto, 2008). For example, using the language of the Big Five, one might expect the autotelic personality to be conscientious (mapping on to persistence), and open to experience (mapping on to curiosity). Nakamura and Csikszentmihalyi (2002) have even identified persistence as a meta-skill that is conducive to entering and staying in flow, which is suggestive of a relation between flow and conscientiousness.

Perhaps unsurprisingly, some researchers have begun to examine how measures of flow proneness relate to the Big Five personality traits. For example Ullén et al., (2012) examined the relation between the SFPQ, a measure of flow proneness, and the Big Five personality traits as measured by the NEO-PI-R (Costa \& McCrae, 2008). The authors proposed that those high in neuroticism are less likely to experience flow because they are less emotionally stable and prone to negative affect, which may interfere with or prevent flow experiences. Regression analyses supported this proposal and also showed that conscientiousness is a significant (positive) predictor of flow proneness (see also, Ullén, Harmat, Theorell, \& Madison, 2016). Ross and Keiser (2014) also found that increased flow proneness is associated with increased conscientiousness and decreased levels of neuroticism (Ross \& Keiser, 2014). However, unlike other studies, they 
found that higher levels of flow proneness were related to higher levels of extroversion and lower levels of agreeableness. (Ross \& Keiser, 2014). Thus, while the relations between flow proneness and some of the Big-Five traits (such as conscientiousness and neuroticism) appear to be robust, the relations between flow proneness and the other big-five traits (such as extraversion and agreeableness) have been less consistent.

Building on the previously reported associations between flow proneness and the Big-Five personality traits, here we investigate the relation of the Big Five personality traits with our new measures of flow that specifically index deep, effortless concentration. We were interested in examining whether the Big Five personality traits would relate to our new flow measures in a similar way as they have been shown to relate to the SFPQ. Because our measures of flow and the SFPQ are based on very different conceptual frameworks, there remains the possibility that they would relate differently to the Big Five personality traits.

In addition to examining differences in personality traits, we also investigate how participant age relates to the tendency to experience flow. Previous research has indicated that flow occurs in both in youthful (Sato, 1988) and elderly populations (Han, 1988), with some indication that the tendency to experience flow may actually increase across the lifespan (Ullén et al, 2016).

\section{The Present Study}

Having advocated for the conceptualization of flow in terms of deep, effortless concentration (our first goal), we sought to address our remaining goals empirically, using an individual differences approach. Our second goal was to create two reliable scales with which to measure flow according to this reconceptualization. Furthermore, we sought not only to measure flow as deep, effortless concentration, but also to develop trait scales that tap the frequency of the flow experience in both internal (e.g. thinking) and external (e.g. a physical task) circumstances. We 
have termed these scales the Deep Effortless Concentration - Internal (DECI) and Deep Effortless Concentration - External (DECE), respectively. Related to this goal, using correlational and factor analyses we also examined whether internal and external flow should be construed as two distinct constructs, or as two manifestation of the same construct. We also included the Swedish Flow Proneness Questionnaire (SFPQ; Ullén et al., 2012) to document the relation between our new flow measures and the SFPQ. A third goal was to elucidate the relation between flow and everyday attention. To address this goal, we examine the relation between the flow measures, and four measures of sustained attention ability in everyday life. These measures probe the frequency of inattentive behaviours such as mindless attention lapses (MAAS-LO), attention-related errors (ARCES), and mind-wandering, both spontaneous (MWS) and deliberate (MWD). A fourth goal was to examine the relation between our new flow scales and the TAS. Recognizing the similarity between the description of flow and absorption, we included the TAS, a gold standard measure of absorption, to verify that our new measures of deep, effortless concentration did not simply recapitulate the TAS. Our final goal was the examine the link between our new measure of flow and various personality characteristics. To this end, we measured included the Big Five Inventory (BFI: John et al, 2008), and also measured participant age.

\section{Method}

\section{Participants}

Three hundred and twenty-eight (328) participants were recruited from Amazon Mechanical Turk and compensated three dollars for completing a survey approximately 30 minutes in length. Following data collection, 22 participants were removed for either (a) failing an initial attention check (see below for details), (b) indicating they had responded to at least some portion of the survey randomly, or, (c) indicating they were not fluent in English. Seven participants were 
removed for not answering these questions. An additional two participants were removed for incomplete responses. This meant that data from 297 participants were analyzed. There was a relatively even distribution of males (165) and females (125), with two non-binary participants (i.e. one genderqueer and genderless $)^{6}$. Participant age was relatively normally distributed, ranging from 18 to 69 years old with a mean of $35.37(\mathrm{SD}=10.01)^{7}$. The sample tended to be highly educated, with the majority of participants having completed at least some college or university (84\%), and with most of the participants being employed outside Mechanical Turk (82\%).

\section{Measures}

Deep Effortless Concentration - Internal (DECI) and External (DECE). In order to measure the prevalence of flow_-defined according to the construct of deep, effortless concentration - in both internal and external contexts, it was necessary to create two novel questionnaires. One of these was designed to measure flow experiences during internal tasks such as thinking, imagining, or remembering; we refer to this measure as the Deep Effortless Concentration - Internal (DECI) scale. The other was designed to index flow during external tasks, such as sports, hobbies, and playing instruments; we refer to this scale as the Deep Effortless Concentration - External (DECE) scale. Each scale is preceded by a brief instruction statement that provides illustrative examples of either internal or external tasks, depending on whether the scale indexed internal (DECI) or external (DECE) flow. The items across the scales were matched for sentence structure, in order to reduce response differences due to surface characteristics. That is, the DECI and DECE were designed to be nearly identical, except for referring to internal or external experiences, and the instructions that precede the questions. Each measure consists of eight items that probe the

\footnotetext{
${ }^{6}$ Four participants listed the same value for their age and gender (e.g. Age $=29$, Gender $=29$ ), and one participant marked an ' $\mathrm{x}$ '. As gender was not a variable of interest for the present study, no participants were removed from analysis on the basis of gender

${ }^{7}$ Skew $=.94$ Kurtosis $=.24$
} 
frequency with which participants experience flow, with questions such as "I can perform an internal/external task so quickly and easily it seems to happen without effort" on a 1 (Never) to 7 (Always) Likert scale. We assume that when responding to these questions (as with any trait measure) participants consult their state experiences and report on how frequently they experience these states. The full set of items for the DECI and DECE are presented in Appendix A.

\section{Mindful Attention Awareness Scale - Lapses Only (MAAS-LO). The MAAS-LO}

(Brown \& Ryan, 2003; Carriere, Cheyne \& Smilek, 2008) assesses the frequency with which individuals behave in an absent-minded or mindless fashion on a 12-item scale. Participants respond to items such as "I rush through activities without being really attentive to them" and "I find myself doing things without paying attention" on a 6-point Likert scale ranging from 1 (almost never) to 6 (almost always). The MAAS-LO has been demonstrated to have good internal consistency (i.e. above .8; Carriere, Cheyne, \& Smilek, 2008; Ralph, Thompson, Cheyne \& Smilek, 2014) and to predict performance on sustained attention tasks (Smilek, Carriere \& Cheyne, 2010).

Attention Related Cognitive Errors Scale (ARCES). The ARCES (Cheyne, Carriere \& Smilek, 2006) is a 12-item self-report measure designed to assess the frequency of everyday performance errors that result from lapses in sustained attention. Participants indicate their responses to statements describing everyday attention errors, such as "I fail to see what I am looking for even though I am looking right at it" or "I have gone to the fridge to get one thing (e.g. milk) and taken something else (e.g. juice)" on a 5-point Likert scale ranging from 1 (never) to 5 (very often). Higher scores on the ARCES have been demonstrated to predict poorer performance on the Sustained Attention to Response Task (SART; Cheyne et al., 2006). The ARCES has been consistently demonstrated to have high internal consistency (Cheyne et al., 2006; Ralph et al., 2014), and to predict errors of commission on a sustained attention task (Smilek et al., 2010). 
Spontaneous and Deliberate Mind-Wandering (MWS and MWD). The Spontaneous Mind-Wandering Scale (MWS; Carriere, Seli \& Smilek, 2013) and Deliberate Mind Wandering Scale (MWD; Carriere et al., 2013) are 4-item subjective report scales that measure individual differences in mind-wandering in everyday life. The MWS measures the tendency to experience unintentional/spontaneous episodes of mind-wandering, while the MWD measures the tendency to experience intentional/deliberative episodes of mind wandering. On the MWS, participants respond to statements such as "I find my mind wandering spontaneously", whereas on the MWD, participants respond to statements such as "I allow my thoughts to wander on purpose". For each scale, participants indicate the frequency with which they experience mind-wandering on a 7-point Likert scale, with response options ranging from 1 (Rarely) to 7 (A lot). Previous research has indicated there is a positive correlation between spontaneous and deliberate mind-wandering (Carriere et al., 2013; Seli, Carriere, \& Smilek, 2015), but that these experiences are dissociable as well (for a review, see Seli, Risko, \& Smilek, 2016). Each of these scales has been demonstrated to have high reliability (Carriere et al., 2013).

Big Five Personality (BFI). The BFI (John, Donahue, \& Kentle, 1991; John, Naumann, \& Soto, 2008) is a 44-item inventory that was created to represent the prototypical definitions of the Big Five personality factors, Extraversion, Agreeableness, Conscientiousness, Neuroticism and Openness. Participants are presented with a series of short statements (e.g. "has an assertive personality", "gets nervous easily") preceded by the phrase "I see myself as someone who...". Participants then indicate how much each statement applies to them on a 5-point Likert scale (where $1=$ "disagree strongly" and $5=$ "Agree strongly"). The BFI captures each of the core traits of personality on a separate subscale, and the subscales for each trait have been demonstrated to 
have reasonable reliability (ranging from .75 to .90) and three-month stability (ranging from .80 to .90) (John et al, 2008).

The Swedish Flow Proneness Questionnaire (SFPQ). The SFPQ (Ullén et al., 2012) assess individual differences in the tendency to experience flow in three domains: at work, during maintenance (i.e. household chores), or during leisure. For each domain, participants are presented with seven items (which are identical across each domain), to which they respond on a five-point Likert scale. The SFPQ measures flow using a global flow approach, such that the items each assess a unique facet of flow experience (i.e. concentration, skill-challenge balance, explicit goals, clear feedback, sense of control, enjoyment, and lack of boredom) and are then averaged together to create a global flow score (for sample items of the SFPQ, see Ullén et al., 2012). We adjusted the instructions for the work domain from "When you do something at work, how often does it happen that...?" to "When you do something at work or school, how often does it happen that...?" to include potential students. In the present study, we evaluated the SFPQ by combining the subscales in order to obtain a total flow score, as has been done previously (de Manzano, Cervenka, Jucaite, Hellenäs, Farde, \& Ullén, 2013; Ullén et al, 2012;). The total flow score has been shown to have higher reliability than the individual subscales (Mosing et al, 2012).

Tellegen Absorption Scale (TAS). The TAS (Tellgen \& Atkinson, 1974; University of Minnesota Press) is a 34-item scale that measures individual differences in absorption, the trait tendency to become deeply immersed in a task or event. The TAS was used with permission of the University of Minnesota Press, who provided the scale items. In administering the test, we followed the recommendations of Kihlstrom (2011), by labelling the TAS with a neutral title, and presenting the items on a 4-point Likert scale ranging from 0 (Never) to 3 (Always). While absorption can be broken down into several subscales (e.g. Enhanced Awareness, or Responsiveness 
to Engaging Stimuli), these subscales are highly inter-correlated, indicating the absorption is a relatively unidimensional construct (Tellegen, 1992). As such we computed only an overall absorption score.

Demographic Survey. Participants were also asked to complete a brief demographics survey following their completion of the other measures. The survey included questions regarding participants' age, education level and status, income, smartphone ownership, employment status, English fluency, and gender.

Attention Check Questions. We included two attention check questions at the end of the survey. In the first attention check participants are presented with a list of hobbies, but rather than indicating their actual interests, they are required to select 'other' and type "I have read the instructions". The second attention check asked participants to indicate whether they had answered any part of the survey randomly. The response to this question did not affect participant remuneration, and participants were informed of this in order to encourage honest responding.

\section{Procedure}

After providing informed consent, participants who agreed to take part in the study were provided with a link to the survey and a password to access it (the password was changed manually every 24 hours). Participants were presented with the DECI, DECE, ARCES, MAAS-LO, MWS, MWD, BFI, and SFPQ. The order in which the scales were presented was randomized for each participant. Furthermore, when any given scale was presented, the order of the items within the scale was randomized as well. To conform with the internet use conditions for the TAS, this questionnaire was presented last to ensure only two items per page were visible at once. Thus, participants were always presented with the TAS following the other measures. Following the completion 
of the TAS, participants were presented with the demographics survey (see Appendix B), and the two attention checks (described above).

\section{Results}

The results of the present study are described in four sections. In the first section we describe the psychometric properties of our measures, with a specific focus on our newly developed flow measures (DECI and DECE). In the second section we analyze the relations between the measures of flow and the measures of inattention (MAAS-LO, ARCES, MWS, MWD), and report the relation between flow experience and age. In the third section we examine the relations between the flow measures and the TAS (indexing absorption). Finally, in the fourth section we analyze the relations between the flow measures and the Big Five personality measures. ${ }^{8}$

\section{Psychometrics}

Descriptive statistics for each of the scales used in the present study are presented in Tables 1 and 2. In general, the measures used in the present study were demonstrated to have acceptable psychometric properties, with Cronbach's Alpha for the measures ranging from .80 to .95 . The two new measures of flow (the DECI and the DECE) were each found to have a good Cronbach's alpha (i.e. above .8$)(\mathrm{DECI}=.95, \mathrm{DECE}=.95)$ indicating these scales had strong internal consistency. The skewness and kurtosis values were also within a reasonable range (i.e. skewness $<2$ and kurtosis $<4$; see Kline, 1998), indicating a relatively normal distribution of scores. Item statistics for the DECI and DECE are presented in Table 3. As can be seen in the tables, the corrected item-total correlation for each item was high (greater than .9), which suggests the items are all tapping a common construct.

\footnotetext{
${ }^{8}$ We ran several previous iterations of this experiment during the development of the items for the internal and external flow scales. Each iteration varied in some way, either with the content of the items, the instructions, or the number of other questionnaires participants were presented with, before we finalized the items and instructions for the present study.
} 


\section{Confirmatory Factor Analysis}

To examine the factor structure of the internal and external flow scales we compared two models using AMOS 24 (Arbuckle, 2016). One possibility was that the items of the internal and external flow scales, rather than being separate factors, could be explained by a single global flow variable. On the other hand, it could be that while correlated, internal and external flow should be considered separate constructs that each influence the responses to the items. To distinguish between these two possible factor structures, we tested two separate measurement models using Confirmatory Factor Analysis (CFA) and examined the fit of each model using the Chi-Square, CFI, RMSEA, and PCLOSE.

For each of the following models the error variances corresponding to the items of the DECI are labelled "el" to "e8", and the error variances corresponding to the items of the DECE are labelled "e9" to "e16". To be clear, "e1" corresponds to the error for "DECI-1" and "e9" corresponds to "DECE-1". Recall that the sentence structure of the items of the DECI and DECE were designed to match (i.e. DECI-1 matches DECE-1, DECI-2 matches DECE-2, and so on). As such, we included covariances between the errors for each pair of items in each of the models (i.e. DECI1/e1 is correlated with DECE1/e9). This was done in order to account for any systematic error variance resulting from the surface characteristics of the items. The reader should note that in the depictions of each of these models (see Figures 1 and 2), the order of the items is reversed for the DECE, which was done to reduce the crossing of lines depicting the correlated errors.

To account for the possibility that all of the items from both the DECI and the DECE are influenced by a single flow factor, we tested a 1-factor measurement model (see Figure 1). This model was found to be of a poor fit $\left(\chi^{2}(96)=1062.01, \mathrm{CFI}=.794, \mathrm{RMSEA}=.184\right.$, PCLOSE $=$ .000 ), indicating that a single flow factor influencing all 16 items is not an appropriate model of 
the data. In the second model (see Figure 2), we tested a 2-factor solution with internal and external flow as separate, correlated factors influencing the response to the items to the two scales. This model was found to be a good fit to the data $\left(\chi^{2}(95)=230.89\right.$, CFI $=.971$, RMSEA $=.070$, PCLOSE $=.003)$, suggesting that internal and external flow are, while correlated, independent constructs that uniquely influence responses to each of the scales. We compared these models directly using a chi-square test. The model with 2 correlated factors was found to fit the data significantly better than the model with a single global factor $\left(\chi^{2}(1)=831.11, p<.01\right)$. These results indicate a 2-factor model is preferable to a 1-factor model, and provided evidence that internal and external flow are distinct concepts. As such, going forward we treat the DECI and DECE as measures of two separate components of the flow experience.

\section{The Relation between Flow and Inattention}

In this section we examine the relations among the measures of inattention (MAAS-LO, ARCES, MWS, MWD) and three measures of flow, using both of our newly developed flow measures (DECI and DECE), and the SFPQ-total. The correlations can be viewed in Table 4. It is worth noting that both the DECI and DECE had a modest correlation with the SFPQ-total, indicating convergent validity between these constructs, but also that the new measures are not redundant with the SFPQ-total.

In general, the tendency to experience flow (as measured by all three scales) had a negative relation with inattention measures. The MAAS-LO, ARCES, and MWS were all significantly negatively correlated with each of the flow measures. An exception was the MWD, which was found to have no significant relation to either the DECI, DECE, or SFPQ. Unlike the other inattention measures, which focus primarily on involuntary types of inattention, scores on the MWD reflect a tendency to engage in inattentive behaviour on purpose, which may explain the non-relation to any 
flow measures. On the whole, these results seem to suggest that an increased propensity to experience flow is related to a decreased tendency to experience involuntary forms of inattention.

\section{Absorption and Flow}

Recall that we included the TAS to evaluate whether our new measures of flow are simply redundant versions of this well-accepted measure of absorption. Scores on the TAS had a significant, positive correlation with scores on the internal $(r=.191)$ and external $(r=.224)$ flow scales. Importantly, the fact that the correlations are relatively modest suggests that the new flow scales are not simply alternative or redundant versions of the TAS. Further evidence that our new measures of flow are distinct from the TAS comes from the relations among these measures and the measures of inattention. Recall that the relation between the flow measures and measures of inattention were generally negative. In contrast, the results showed that the relation between the TAS and each of the four measures of inattention were positive, with correlations ranging from .267 (TAS and MAAS-LO) to .448 (TAS and MWD) (see Table 4). That our measures of flow and the measure of absorption had opposite patterns of relations with the inattention measures further reinforces the notion that DECI and DECE are distinct from the TAS, and establishes discriminant validity for these scales. Interestingly, the TAS did not have a significant relation with scores on the SFPQ $(r=.062)$. The full set of correlations between absorption, flow, and inattention can be viewed in Table 4 .

\section{Personality and Flow}

Extraversion, Agreeableness, Conscientiousness and Openness were all found to have a significant positive relation with each of the three flow measures, while Neuroticism showed significant negative relations with the flow measures (see Table, 5). These results are consistent with expectations and findings from previous research. Another notable finding was the relation between flow and participant age (see Table 4). Specifically, both the DECE and the SFPQ had a 
small, but significant correlation with age, such that older participants tended to experience these forms of flow more frequently.

\section{General Discussion}

In the Introduction we outlined our reasons for conceptualizing flow as deep, effortless concentration. Our second (closely related) goal was to create two reliable scales with which to measure flow according to this reconceptualization. More specifically, the two new flow scales assessed individual differences in the propensity to experience flow in internal contexts, such as while thinking (the DECI), as well as external contexts, such as playing a sport (the DECE). The development of the DECI was of particular interest, as flow in internal states (such as daydreaming), has been relatively ignored in the flow literature, possibly because certain facets do not readily translate across different contexts. The results of the present study demonstrated that these scales have excellent psychometric properties and that the measured concepts of internal and external flow are highly correlated. This suggests that individual differences in the propensity to experience flow are consistent across internal and external contexts. Further, the DECI and DECE had a similar pattern of relations with the another measure of flow (the SFPQ), as well as with measures of inattention, absorption and the Big Five personality traits. While the foregoing findings might suggest that internal and external flow are identical constructs, using confirmatory factor analysis we found that a model treating the DECI and DECE as two separate but correlated factors was a significantly better fit to the data than a model with a single factor underlying both scales. Thus, the results of the factor analysis suggested internal and external flow are better conceived as correlated, but separable constructs.

Importantly, the major difference between our new scales and other measures of flow proneness (such as the SFPQ and DFS-2) is in the fundamental strategy used to assess flow. 
While the SFPQ and DFS-2 attempt to measure flow by assessing multiple putative facets of flow and averaging across the facets to create a global flow score, the DECI and DECE index flow by measuring the frequency with which participants endorse the single experience of deep, effortless concentration. As we noted in the Introduction, we believe our approach has several key advantages: Specifically, our conceptualization 1) treats flow with more specificity (as a single experience rather than an ever shifting combination of multiple facets), 2) allows for a cleaner separation of flow from the causes and consequences of flow and 3) allows for the possibility of measuring flow across a wider range of contexts (e.g., both external and internal contexts).

In addition to the foregoing benefits, our approach also avoids several thorny conceptual/measurement issues that arise with prior multi-faceted global flow conceptualizations/measures. For instance, a potential drawback of prior multi-faceted global measures of flow is that participants could achieve a high global flow score by experiencing each flow facet frequently, but not simultaneously ${ }^{9}$. Critically, such high global flow scores would not clearly indicate the presence of flow according to the multi-faceted global flow view, because, for flow to be present, this view requires most (if not all) of the facets be experienced simultaneously. Another potential drawback of multi-faceted global flow measures is that they may be used to index flow even when the researchers might define flow (either implicitly or explicitly) primarily in terms of the core facet of deep, effortless concentration. The summing of scores across multiple facets would make it unclear whether differences in the summed global flow score truly measure

\footnotetext{
9 This is considerably more problematic for a trait scale, where individuals could experience each facet in entirely different contexts. For example a frequent experience of clear goals at work, a frequent loss of self-consciousness while driving, and action-awareness merging while doodling.
} 
changes in the assumed core facet of flow. Indeed, there could be changes in 'global flow' without there being changes in deep, effortless concentration, simply because there were changes in all of the other putative facets of flow. Our suggestion of both explicitly conceptualizing flow as deep, effortless concentration, and then directly measuring this experience clearly avoids these potential pitfalls.

Our third goal was to address how individual differences in the tendency to experience flow related to the experience of everyday inattention. Previous research into the relation between flow and sustained attention has led to conflicting conclusions, with some claiming there is no relation between flow and sustained attention ability (Ullén et al, 2010; 2012; 2016), while other research suggests superior sustained attention abilities are positively related to flow (Cermakova et al, 2010; Moore, 2013). Uniquely, the present study examined the relation between flow and everyday inattention. The results demonstrated that flow, whether measured according to the key facet of deep, effortless concentration (i.e. using our DECI and DECE scales) or the sum of multiple facets (SFPQ), was negatively related to general absent-mindedness, attention-related cognitive errors, and spontaneous mind-wandering. Thus, those individuals who experience flow more often seem to be more focused, and less prone to attention errors (such as pouring their orange juice into their coffee), or allowing their thoughts to wander away from the task at hand.

Our fourth goal was to assess whether our new measures of flow (DECI and DECE) were simply re-capitulating the gold standard measure of absorption, namely, the TAS (Tellegen \& Atkinson, 1974). Our results showed that the DECI and DECE both have a modest positive correlation with the TAS, suggesting that these measures capture some common variance, but importantly, that they are not redundant. Another way in which these measures are distinct is in their relations to everyday attention. Those who score higher on the DECI and DECE reported 
that they experience relatively less absent-mindedness, fewer attention-related errors, and less spontaneous mind-wandering in their everyday lives. In contrast, those who scored higher on the TAS experienced relatively more of each of these types of inattention, while also engaging in deliberate mind-wandering more frequently. Thus, our new measures of flow (i.e. the DECI \& DECE) are clearly not redundant with the TAS.

Beyond describing the relations among flow and absorption measures, it might be useful if we speculated about the conceptual interpretations of the measures and their relations. Any such speculations, however, would depend on the assumptions that are made about the definitions of flow and absorption, as well as the assumptions that are made about the validity of the measures used. On the one hand, one could assume that each of the measures are reasonably valid indices of their respective constructs. Based on this assumption the pattern of findings in the present study could be interpreted as showing that flow and absorption are distinct, but related constructs. On the other hand, one could assume that flow and absorption are in fact the same construct, which is an assumption that seems to be endorsed in the flow literature (Crust \& Swann, 2013; Csikszentmihalyi, 1990; Csikszentmihalyi \& Nakamura, 2002; Harari, 2008; Jackson \& Marsh, 1996; Martin \& Jackson, 2008; Peifer et al., 2014; Ullén et al., 2010, Wright et al., 2006; Wright et al., 2007). Based on this rather different assumption, one would conclude that at least some of the measures are not valid indices of the underlying concepts. For example, the lack of a significant correlation between the SFPQ and the TAS would indicate that one or both of these measures is a poor index of the underlying flow/absorption construct.

Perhaps one way to move forward with these measurement and conceptual issues is to posit that the various measures of flow and absorption (DECI, DECE, SFPQ, \& TAS) reflect different aspects of a general flow/absorption experience. This might partly be due to the different 
measurement strategies employed by the various measures. To remind, the TAS measures absorption indirectly, by assessing a variety of different experiences, some of which seem to focus on dissociative or negative absorptive states. In contrast, the SFPQ measures flow by assessing multiple facets, such as having clear goals, feeling in control, and avoiding boredom, which all seem to focus on more positive absorptive states. Finally, the DECI and DECE measure flow by directly assessing the frequency of deep, effortless concentration, without specific reference to positive or negative manifestations of this deep level of engagement. Thus, it could be that the DECI and DECE tap the general construct of deep, effortless concentration, the TAS taps some of this general construct, but also a variety of other mostly negative states, and the SFPQ taps the general construct (with virtually no overlap with the TAS), plus other mostly positive experiences (i.e., perhaps positive precursors and consequences of positive engagement states). However, it is important to keep in mind that these distinctions are only speculative at this time.

Finally, the fifth goal was to measure the relations between the different scales of flow and the Big Five personality traits (as measured by the BFI). For all three measures of flow (the DECI, DECE, and SFPQ), we found a positive relationship with extraversion, agreeableness, conscientiousness, and openness. Neuroticism was negatively related to each of these three flow measures. These results are in line with both previous research (e.g. Ullén et al., 2012), and what would be expected according to prior descriptions of flow prone individuals (Nakamura \& Csikszentmihalyi, 2002). The positive relation between flow and openness is particularly interesting, as openness is one of the traits used to describe the autotelic personality (in addition to curiosity, low self-centeredness, and doing things for their intrinsic value; Nakamura \& Csikszentmihalyi, 2002). Overall, the pattern of relations observed with personality supports the DECI and DECE as valid measures of flow. 


\section{Future Directions}

The present findings suggest several directions for future research. First, given the relation between flow and everyday inattention, it might be worthwhile to examine the relation between flow and other variables related to everyday inattention, such as the tendency to engage in media multi-tasking (e.g. watching Netflix and surfing the internet simultaneously). The available evidence suggests individuals who engage in a high degree of media multi-tasking also report experiencing more everyday attention lapses (Ralph et al., 2014). Conceivably, this sort of behaviour could reduce the depth or frequency of flow experience by preventing the individual from achieving the singular narrowing of focus that is characteristic of flow. Alternatively, because listening to music has been reported as an effective way to facilitate flow in athletes in several case studies (Pain, Harwood, \& Anderson, 2011; Pates, Karageorghis, Fryer, \& Maynard, 2003), it is possible that some forms of media multi-tasking could be used to facilitate flow. Perhaps one way to reconcile these opposing findings is by noting that people can engage in media multi-tasking strategically (Ralph, Seli, Wilson, \& Smilek, under review; Wang, Irwin, Cooper, \& Srivastava, 2015; see also Ralph, 2017), and that media multi-tasking may have differential effects on flow at different levels of primary task difficulty. For example, in circumstances in which the primary task is relatively easy (e.g. marking tests), media multi-tasking behaviour (e.g., listening to music) could be leveraged to increase perceived task difficulty, and make flow more likely (i.e. by leading to a more optimal level of skill-challenge balance). In other circumstances, however, in which the primary task is already quite difficult (e.g., writing), some forms of demanding media multi-tasking (e.g., watching a YouTube video) might shift people away from an optimal level of task difficulty into a situation of overload, thus reducing the likelihood of flow. 
A second and related avenue would be to explore the relation between flow and smartphone use. On the one hand, given that smartphone use is related to everyday inattention (Marty-Dugas, Ralph, \& Smilek, 2018), it seems possible that frequent smartphone use might reduce the occurrence of flow experiences. On the other hand, some have suggested smartphones can be used as a way to facilitate flow experiences (Levitin, 2014).

Finally, the present findings show that internal flow is, to some extent, distinct from external flow, which suggests that examining the relatively understudied concept of internal flow might be another fruitful avenue for future research. Because flow is known to depend on task difficulty (Harmat et al., 2015; Kennedy, Miele, \& Metcalfe, 2014), one possible future direction would be to examine whether varying the difficulty of internal thinking tasks influences the likelihood of experiencing internal flow states in a laboratory setting. Interestingly, there already seems to be some indication that this might be the case: A study reported by Keller, Ringelhan, and Blomann, (2011, Experiment 2) demonstrated that the degree of skill-challenge balance experienced during a memory-based quiz game predicted intrinsic motivation to engage in the quiz again. Because the memory-based game is likely an internal task, and intrinsic motivation is a known correlate of flow (Kennedy et al, 2014), the results suggest that varying the difficulty of internal tasks might influence levels of flow. As this and the foregoing examples suggest, the present findings open doors to a host of new research directions. 


\section{Compliance with Ethical Standards}

All procedures performed in studies involving human participants were in accordance with the ethical standards of the institutional and/or national research committee and with the 1964 Helsinki declaration and its later amendments or comparable ethical standards. The data generated and analyzed for the current study are available online in the database Open ICPSR. The title is Deep, Effortless Concentration: Re-examining the Flow Concept and exploring relations with Inattention, Absorption, and Personality - September 2017, Waterloo, Ontario, Canada. The persistent link for this data is http://doi.org/10.3886/E100982V1. The authors declare they have no conflict of interest. 


\section{References}

Aherne, C., Moran, A. P., \& Lonsdale, C. (2011). The effect of mindfulness training on athletes' flow: An initial investigation. The Sport Psychologist, 25(2), 177-189.

Arbuckle, J. L. (2016). Amos (Version 24.0) [Computer Program]. Chicago: IBM SPSS.

Asakawa, K. (2010). Flow experience, culture, and well-being: How do autotelic Japanese college students feel, behave, and think in their daily lives?. Journal of Happiness Studies, 11(2), 205-223.

Brown, K. W., \& Ryan, R. M. (2003). The benefits of being present: mindfulness and its role in psychological well-being. Journal of personality and social psychology, 84(4), 822.

Bishop, S. R., Lau, M., Shapiro, S., Carlson, L., Anderson, N. D., Carmody, J., ... \& Devins, G. (2004). Mindfulness: A proposed operational definition. Clinical psychology: Science and practice, 11(3), 230-241.

Carriere, J. S. A., Cheyne, J. A., \& Smilek, D. (2008). Everyday attention lapses and memory failures: The affective consequences of mindlessness. Consciousness and Cognition, 17(3), 835-847. doi:10.1016/j.concog.2007.04.008

Carriere, J. S. A., Seli, P., \& Smilek, D. (2013). Wandering in Both Mind and Body: Individual Differences in Mind Wandering and Inattention Predict Fidgeting. Canadian Journal of Experimental Psychology/Revue Canadienne De Psychologie Expérimentale, 67(1), 1931. doi:10.1037/a0031438

Catley, D. E. L. W. Y. N., \& Duda, J. L. (1997). Psychological antecedents of the frequency and intensity of flow in golfers. International Journal of Sport Psychology, 28(4), 309-322.

Cermakova, L., Moneta, G. B., \& Spada, M. M. (2010). Dispositional flow as a mediator of the 
relationships between attentional control and approaches to studying during academic examination preparation. Educational Psychology, 30(5), 495-511.

Cheyne, J. A., Carriere, J. S. A., \& Smilek, D. (2006). Absent-mindedness: Lapses of conscious awareness and everyday cognitive failures. Consciousness and Cognition, 15(3), 578592. doi:10.1016/j.concog.2005.11.009

Costa, P. T., \& McCrae, R. R. (2008). The revised neo personality inventory (neo-pi-r). The SAGE handbook of personality theory and assessment, 2, 179-198.

Crawford, H. J., Brown, A. M., \& Moon, C. E. (1993). Sustained attentional and disattentional abilities: Differences between low and highly hypnotizable persons. Journal of Abnormal Psychology, 102(4), 534.

Crust, L., \& Swann, C. (2013). The relationship between mental toughness and dispositional flow. European Journal of Sport Science, 13(2), 215-220.

Csikszentmihalyi, M. (1978). Attention and the Holistic Approach to Behaviour. In K.S. Pope \& J.L. Singer (Eds.), The Stream of Consciousness (pp. 335-358) New York: Plenum.

Csikszentmihalyi, M. (1988). The flow experience and its significance for human psychology. In M. Csikszentmihalyi \& I.S. Csikszentmihalyi (Eds.), Optimal experience: Psychological studies of flow in consciousness (pp. 15-35). Cambridge: Cambridge University Press.

Csikszentmihalyi, M. (2000). Beyond boredom and anxiety. Jossey-Bass. (Original work published 1975).

Csikszentmihalyi, M., \& LeFevre, J. (1989). Optimal experience in work and leisure. Journal of personality and social psychology, 56(5), 815.

Csikszentmihalyi, M., \& Nakamura, J. (2010). Effortless attention in everyday life: A systematic 
phenomenology. In B. Bruya (Ed.), Effortless attention: A new perspective in the cognitive science of attention and action (pp. 179-190). Cambridge, MA: The MIT Press.

de Manzano, Ö., Cervenka, S., Jucaite, A., Hellenäs, O., Farde, L., \& Ullén, F. (2013). Individual differences in the proneness to have flow experiences are linked to dopamine D2-receptor availability in the dorsal striatum. Neuroimage, 67, 1-6.

Derryberry, D., \& Reed, M. A. (2002). Anxiety-related attentional biases and their regulation by attentional control. Journal of abnormal psychology, 111(2), 225.

Feldman, G., Hayes, A., Kumar, S., Greeson, J., \& Laurenceau, J. P. (2007). Mindfulness and emotion regulation: The development and initial validation of the Cognitive and Affective Mindfulness Scale-Revised (CAMS-R). Journal of Psychopathology and Behavioral Assessment, 29(3), 177.

Hamari, J., \& Koivisto, J. (2014). Measuring flow in gamification: Dispositional flow scale-2. Computers in Human Behavior, 40, 133-143.

Harmat, L., de Manzano, Ö., Theorell, T., Högman, L., Fischer, H., \& Ullén, F. (2015). Physio logical correlates of the flow experience during computer game playing. International Journal of Psychophysiology, 97(1), 1-7.

Han, S. (1988). The relationship between life satisfaction and flow in elderly Korean immigrants. In M. Csikszentmihalyi \& I.S. Csikszentmihalyi (Eds.), Optimal experience: Psychological studies of flow in consciousness (pp. 138-149). Cambridge: Cambridge University Press.

Harari, Y. N. (2008). Combat flow: Military, political, and ethical dimensions of subjective wellbeing in war. Review of General Psychology, 12(3), 253.

Hockey, R. (2013). The psychology of fatigue: work, effort and control. Cambridge University 
Press.

Jackson, S. A., \& Eklund, R. C. (2002). Assessing flow in physical activity: The flow state scale-2 and dispositional flow scale-2. Journal of Sport and Exercise Psychology, 24(2), 133-150.

Jackson, S. A., Ford, S. K., Kimiecik, J. C., \& Marsh, H. W. (1998). Psychological correlates of flow in sport. Journal of Sport and exercise Psychology, 20(4), 358-378.

Jackson, S. A., \& Marsh, H. W. (1996). Development and validation of a scale to measure opti mal experience: The Flow State Scale. Journal of sport and exercise psychology, 18(1), $17-35$.

Jackson, S. A., Thomas, P. R., Marsh, H. W., \& Smethurst, C. J. (2001). Relationships between flow, self-concept, psychological skills, and performance. Journal of applied sport psychology, 13(2), 129-153.

John, O. P., Donahue, E. M., \& Kentle, R. L. (1991). The Big Five Inventory--Versions 4a and 54. Berkeley, CA: University of California, Berkeley, Institute of Personality and Social Research.

John, O. P., Naumann, L. P., \& Soto, C. J. (2008). Paradigm shift to the integrative Big Five trait taxonomy: History, measurement, and conceptual issues. In O. P. John, R. W. Robins, \& L. A. Pervin (Eds.), Handbook of personality: Theory and research (pp. 114-158). New York, NY: Guilford Press.

Keller, J., Ringelhan, S., \& Blomann, F. (2011). Does skills-demands compatibility result in intrinsic motivation? Experimental test of a basic notion proposed in the theory of flow-experiences. The Journal of Positive Psychology, 6(5), 408-417.

Kennedy, P., Miele, D. B., \& Metcalfe, J. (2014). The cognitive antecedents and motivational 
consequences of the feeling of being in the zone. Consciousness and cognition, 30, 4861.

Kihlstrom, J.F. (2011). Tellegen Absorption Scale. Retrieved from http://socrates.berke ley.edu/\%7Ekihlstrm/TAS.htm

Kline, R. B. (1998). Principles and practice of structural equation modelling. New York: Guilford Press.

Landhäußer, A., \& Keller, J. (2012). Flow and its affective, cognitive, and performance-related consequences. In Advances in flow research (pp. 65-85). Springer New York.

Lee, E. (2005). The relationship of motivation and flow experience to academic procrastination in university students. The Journal of Genetic Psychology, 166(1), 5-15.

Macbeth, J. (1988). Ocean cruising. In M. Csikszentmihalyi \& I.S. Csikszentmihalyi (Eds.), $O p$ timal experience: Psychological studies of flow in consciousness (pp. 214-231). Cambridge: Cambridge University Press.

Martin, A. J., \& Jackson, S. A. (2008). Brief approaches to assessing task absorption and en hanced subjective experience: Examining 'short'and 'core'flow in diverse performance domains. Motivation and Emotion, 32(3), 141-157.

Marty-Dugas, J., Ralph, B. C. W., Oakman, J. M., \& Smilek, D. (2018). The relation between smartphone use and everyday inattention. Psychology of Consciousness: Theory, Research, and Practice, 5(1), 46-62. http://dx.doi.org/10.1037/cns0000131.

Moore, B. A. (2013). Propensity for experiencing flow: The roles of cognitive flexibility and mindfulness. The Humanistic Psychologist, 41(4), 319.

Mosing, M. A., Magnusson, P. K., Pedersen, N. L., Nakamura, J., Madison, G., \& Ullén, F. 
(2012). Heritability of proneness for psychological flow experiences. Personality and Individual Differences, 53(5), 699-704.

Nadon, R., Hoyt, I. P., Register, P. A., \& Kihlstrom, J. F. (1991). Absorption and hypnotizability: Context effects reexamined. Journal of Personality and Social Psychology, 60(1), 144.

Nakamura, J., \& Csikszentmihalyi, M. (2002). The concept of flow. In C. R. Snyder \& S. J. Lopez (Eds.), Handbook of positive psychology (pp. 89 -105). New York: Oxford University Press.

Pain, M. A., Harwood, C., \& Anderson, R. (2011). Pre-competition imagery and music: The impact on flow and performance in competitive soccer. The Sport Psychologist, 25(2), 212232.

Pates, J., Karageorghis, C. I., Fryer, R., \& Maynard, I. (2003). Effects of asynchronous music on flow states and shooting performance among netball players. Psychology of Sport and Exercise, 4(4), 415-427.

Peifer, C., Schulz, A., Schächinger, H., Baumann, N., \& Antoni, C. H. (2014). The relation of flow-experience and physiological arousal under stress - can u shape it?. Journal of Experimental Social Psychology, 53, 62-69.

Ralph, B.C. (2017). Media multitasking and performance on attentionally demanding tasks (Doctoral Thesis). Retrieved from https://uwspace.fuwaterloo.ca/handle/10012/12098.

Ralph, B.C., Seli, P., Wilson, K.E., \& Smilek, D. (Under Review). Volitional media multitasking: Awareness of performance costs and modulation of media multitasking as a function of task demand. Psychological Research.

Ralph B.C., Thomson D.R., Cheyne J.A., \& Smilek D. (2014) Media multitasking and failures of 
attention in everyday life. Psychological Research, 78(5), 661-669.

http://dx.doi.org/10.1007/s00426-013-0523-7

Raven. J. C. (1962). Advanced Progressive Matrices. Set II. London: H. K. Lewis \& Co. Distributed in the USA by The Psychological Corporation. San Antonio. Texas.

Raven. J. C. (1965). Advanced Progressive Matrices. Sets I and II. London: H. K. Lewis \& Co. Distributed in the USA by The Psychological Corporation. San Antonio, Texas.

Ross, S. R., \& Keiser, H. N. (2014). Autotelic personality through a five-factor lens: Individual differences in flow-propensity. Personality and individual differences, 59, 3-8.

Sato, I. (1988). Bosozoku: Flow in Japanese motorcycle gangs. In M. Csikszentmihalyi \& I.S. Csikszentmihalyi (Eds.), Optimal experience: Psychological studies of flow in consciousness (pp. 92-117). Cambridge: Cambridge University Press.

Seli, P., Carriere, J., \& Smilek, D. (2015). Not all mind wandering is created equal: dissociating deliberate from spontaneous mind wandering. Psychological Research, 79(5), 750-758. doi:10.1007/s00426-014-0617-x

Seli, P., Risko, E. F., \& Smilek, D. (2016). Assessing the associations among trait and state levels of deliberate and spontaneous mind wandering. Consciousness and Cognition, 41, 5056. doi:10.1016/j.concog.2016.02.002

Sirois, F. M. (2014). Absorbed in the moment? An investigation of procrastination, absorption and cognitive failures. Personality and individual differences, 71, 30-34.

Smilek, D., Carriere, J. S., \& Cheyne, J. A. (2010). Out of mind, out of sight: eye blinking as indicator and embodiment of mind wandering. Psychological Science, 21(6), 786-789.

Smyser, C. H., \& Baron, D. A. (1993). Hypnotizability, absorption, and subscales of the Dissoci- 
ative Experiences Scale in a nonclinical population. Dissociation: Progress in the Dissociative Disorders.

Stavrou, N. A., Jackson, S. A., Zervas, Y., \& Karteroliotis, K. (2007). Flow experience and athletes' performance with reference to the orthogonal model of flow. The Sport Psychologist, 21(4), 438-457.

Swann, C., Keegan, R. J., Piggott, D., \& Crust, L. (2012). A systematic review of the experience, occurrence, and controllability of flow states in elite sport. Psychology of Sport and Exercise, 13(6), 807-819.

Swann, C. (2016). Flow in Sport. In L. Harmat, F.O. Anderson, F. Ullén, J. Wright, \& G. Sadlo (Eds.), Flow Experience (pp. 267-288). Springer International Publishing.

Tellegen, A., \& Atkinson, G. (1974). Openness to absorbing and self-altering experiences ("ab sorption"), a trait related to hypnotic susceptibility. Journal of abnormal psychology, 83(3), 268.

Tellegen, A. (1992, August). Note on structure and meaning of the MPQ Absorption scale. Unpublished manuscript, University of Minnesota.

Ullén, F., de Manzano, Ö., Almeida, R., Magnusson, P. K., Pedersen, N. L., Nakamura, J., ... \& Madison, G. (2012). Proneness for psychological flow in everyday life: Associations with personality and intelligence. Personality and Individual Differences, 52(2), 167-172.

Ullén, F., de Manzano, Ö., Theorell, T., \& Harmat, L. (2010). 10 The Physiology of Effortless Attention: Correlates of State Flow and Flow Proneness. Effortless attention: A new perspective in the cognitive science of attention and action, 205.

Ullén, F., Harmat, L., Theorell, T., \& Madison, G. (2016). Flow and individual differences-a 
phenotypic analysis of data from more than 10,000 twin individuals. In L. Harmat, F.O. Anderson, F. Ullén, J. Wright, \& G. Sadlo (Eds.), Flow Experience (pp. 267-288). Springer International Publishing.

Ulrich, M., Keller, J., Hoenig, K., Waller, C., \& Grön, G. (2014). Neural correlates of experimentally induced flow experiences. Neuroimage, 86, 194-202.

Ulrich, M., Keller, J., \& Grön, G. (2016). Neural signatures of experimentally induced flow ex periences identified in a typical fMRI block design with BOLD imaging. Social cognitive and affective neuroscience, 11(3), 496-507.

Wang, Z., Irwin, M., Cooper, C., \& Srivastava, J. (2015). Multidimensions of media multitasking and adaptive media selection. Human Communication Research, 41(1), 102-127.

Wright, J. J., Sadlo, G., \& Stew, G. (2006). Challenge-skills and mindfulness: An exploration of the conundrum of flow process. OTJR: Occupation, participation and health, 26(1), 2532.

Wright, J. J., Sadlo, G., \& Stew, G. (2007). Further explorations into the conundrum of flow process. Journal of Occupational Science, 14(3), 136-144. 
Table 1 Descriptive statistics for measures of flow and inattention $(n=297)$

\begin{tabular}{lccccc}
\hline & Mean & SD & Skew & Kurtosis & $\alpha$ \\
\hline DECI & 4.89 & 1.216 & -.50 & -.08 & .95 \\
DECE & 5.01 & 1.190 & -.49 & -.15 & .95 \\
SFPQ (Total) & 3.57 & .522 & -.14 & -.20 & .87 \\
MAAS-LO & 2.71 & .930 & .22 & -.44 & .90 \\
ARCES & 2.52 & .739 & .59 & .79 & .93 \\
MWS & 3.59 & 1.467 & -.02 & -.77 & .88 \\
MWD & 4.47 & 1.489 & -.41 & -.36 & .90 \\
\hline
\end{tabular}

Note. DECI = Deep Effortless Concentration - Internal; DECE = Deep Effortless Concentration - External; SFPQ = Swedish Flow Proneness Questionnaire; MAAS-LO = Mindful Attention Awareness Scale - Lapses Only; ARCES = Attention Related Cognitive Errors Scale; MWS $=$ Mind-Wandering Spontaneous; MWD = Mind-Wandering Deliberate. Skew SE = .141 Kurtosis $\mathrm{SE}=.282$ 
Table 2 Descriptive statistics for absorption and personality measures $(n=297)$

\begin{tabular}{lccccc}
\hline & Mean & SD & Skew & Kurtosis & $\alpha$ \\
\hline TAS & 2.22 & .591 & .34 & .11 & .95 \\
Extraversion & 2.92 & 1.001 & -.11 & -.86 & .90 \\
Agreeableness & 3.83 & .767 & -.51 & -.18 & .86 \\
Conscientiousness & 4.01 & .783 & -.72 & -.19 & .89 \\
Neuroticism & 2.53 & .974 & .40 & -.50 & .89 \\
Openness & 3.76 & .779 & -.79 & .73 & .87 \\
\hline
\end{tabular}

Note. TAS $=$ Tellegen Absorption Scale. Skew SE $=.141$ Kurtosis SE $=.282$ 
Table 3 Item statistics for internal flow (DECI) and external flow (DECE) measures $(n=297)$

\begin{tabular}{|c|c|c|c|c|c|c|c|}
\hline Item & Mean & $\mathrm{SD}$ & $\begin{array}{l}\text { Corrected } \\
\text { Item-Total } \\
\text { Correlation }\end{array}$ & Item & Mean & SD & $\begin{array}{l}\text { Corrected } \\
\text { Item-Total } \\
\text { Correlation }\end{array}$ \\
\hline DECI 1 & 4.91 & 1.29 & .820 & DECE 1 & 5.00 & 1.25 & .812 \\
\hline DECI 2 & 4.99 & 1.34 & .811 & DECE 2 & 5.10 & 1.31 & .814 \\
\hline DECI 3 & 4.85 & 1.49 & .736 & DECE 3 & 4.96 & 1.43 & .741 \\
\hline DECI 4 & 4.66 & 1.49 & .865 & DECE 4 & 4.77 & 1.45 & .842 \\
\hline DECI 5 & 4.86 & 1.41 & .876 & DECE 5 & 4.94 & 1.39 & .847 \\
\hline DECI 6 & 4.92 & 1.39 & .832 & DECE 6 & 5.02 & 1.38 & .846 \\
\hline DECI 7 & 4.99 & 1.39 & .820 & DECE 7 & 5.09 & 1.38 & .865 \\
\hline DECI 8 & 5.03 & 1.40 & .841 & DECE 8 & 5.20 & 1.36 & .842 \\
\hline
\end{tabular}


Table 4 Correlations among flow, inattention, and absorption; age is also included $(n=297)$

\begin{tabular}{|c|c|c|c|c|c|c|c|c|}
\hline & DECI & DECE & SFPQ & TAS & MAASLO & ARCES & MWS & MWD \\
\hline \multicolumn{9}{|l|}{ DECI } \\
\hline DECE & $.703^{* *}$ & & & & & & & \\
\hline SFPQ & $.565^{* *}$ & $.579^{* *}$ & & & & & & \\
\hline TAS & $.191^{* *}$ & $.224^{* *}$ & .062 & & & & & \\
\hline MAASLO & $-.376^{* *}$ & $-.320^{* *}$ & $-.450^{* *}$ & $.267^{* *}$ & & & & \\
\hline ARCES & $-.362^{* *}$ & $-.286^{* *}$ & $-.365^{* *}$ & $.387^{* *}$ & $.650^{* *}$ & & & \\
\hline MWS & $-.356^{* *}$ & $-.323^{* *}$ & $-.410^{* *}$ & $.333^{* *}$ & $.547^{* *}$ & $.590^{* *}$ & & \\
\hline MWD & .014 & -.009 & -.073 & $.448^{* *}$ & $.233^{* *}$ & $.285^{* *}$ & $.512^{* *}$ & \\
\hline $\mathrm{AGE}$ & .093 & $.122^{*}$ & $.219^{* *}$ & -.094 & -.087 & -.011 & -.101 & -.105 \\
\hline
\end{tabular}

Note. DECI = Deep Effortless Concentration - Internal; DECE = Deep Effortless Concentration - External; SFPQ = Swedish Flow Proneness Questionnaire; TAS = Tellegen Absorption Scale; MAAS-LO = Mindful Attention Awareness Scale - Lapses Only; ARCES = Attention Related Cognitive Errors Scale; MWS = Mind-Wandering Spontaneous; MWD = Mind-Wandering Deliberate. $* * p<.01 * p<.05$ (2-tailed) 
Table 5 Correlations among flow and the Big Five Inventory $(n=297)$

\begin{tabular}{lccc}
\hline & DECI & DECE & SFPQ \\
\hline Extraversion & $.282^{* *}$ & $.341^{* *}$ & $.300^{* *}$ \\
Agreeableness & $.276^{* *}$ & $.341^{* *}$ & $.463^{* *}$ \\
Conscientious & $.571^{* *}$ & $.542^{* *}$ & $.639^{* *}$ \\
Neuroticism & -.374 & $-.446^{* *}$ & $-.398^{* *}$ \\
Openness & $.434^{* *}$ & $.413^{* *}$ & $.351^{* *}$ \\
\hline
\end{tabular}

Note. $* * p<.001,(2$-tailed) 


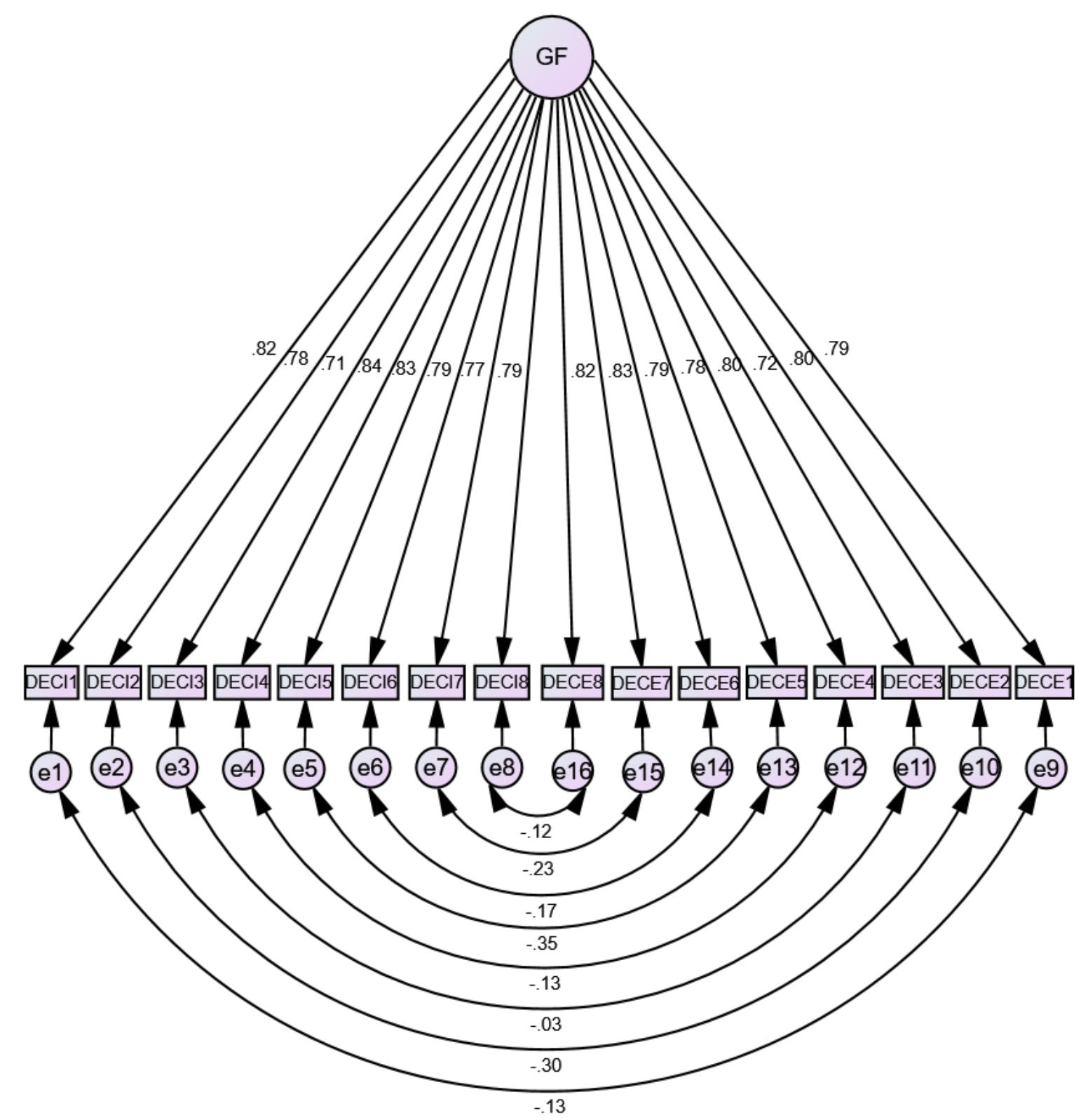

Figure 1. Items of internal and external flow modelled as tapping a single flow construct. Parameter estimates are in standardized form. 


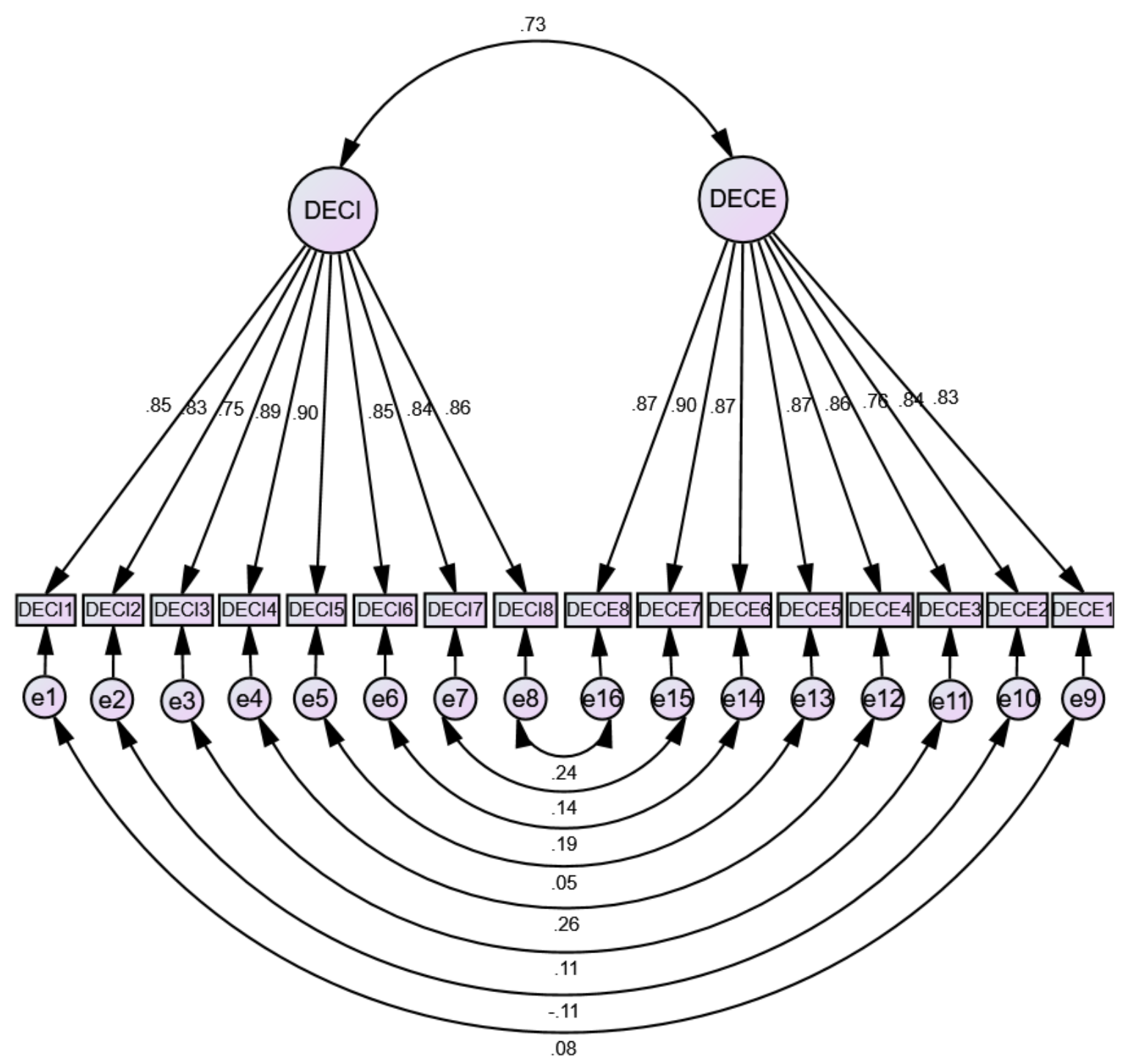

Figure 2. Items of internal and external flow modelled as tapping two correlated constructs (DECI and DECE). Parameter estimates are in standardized form. 


\section{Appendix A - DEC scales (Internal and External)}

\section{The Deep Effortless Concentration Scale - Internal}

Please indicate how often you have each of the following experiences during an internal task (e.g. while thinking, remembering, or imagining) on the 1-7 Scale:

I can achieve a level of deep concentration on my thoughts quickly and automatically
1 Never
7 Always

I am able to completely focus on my thoughts without straining to pay attention

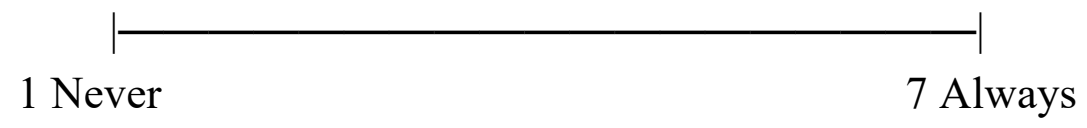

I feel like I don't have to force myself to keep fully engaged with my thoughts

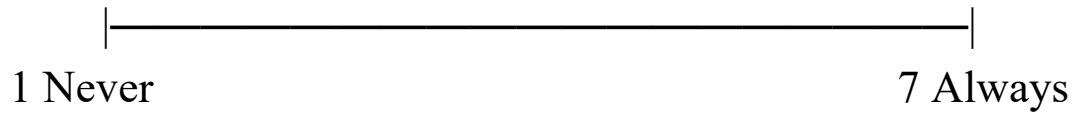

I seem to reach a deep level of focus almost effortlessly

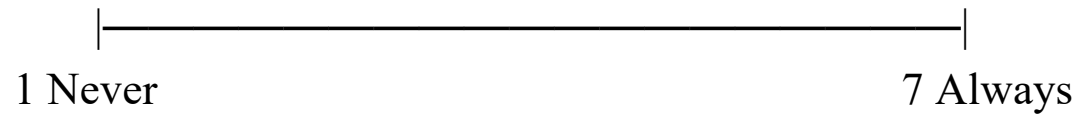

When thinking, I get completely engaged without having to work at it

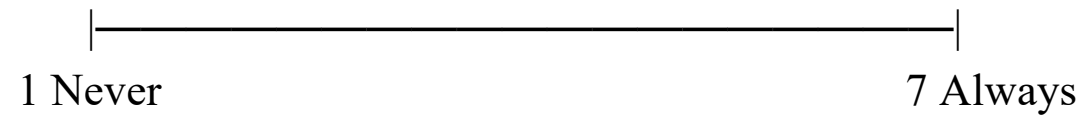

I get in the zone and don't have to force myself to concentrate on my thoughts

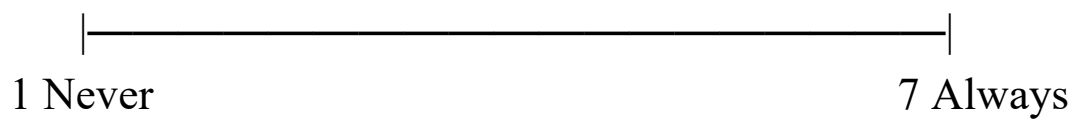

I can naturally and effortlessly sustain my full attention on my thoughts
1 Never
7 Always 
I can easily pay total attention to my thoughts for extended periods of time

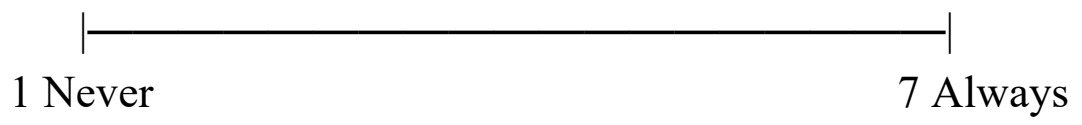

\section{The Deep Effortless Concentration Scale - External}

Please indicate how often you have each of the following experiences during an external task (e.g. practicing a musical instrument, playing a sport, engaging in a hobby) on the 1-7 scale:

I can achieve a level of deep concentration on a task quickly and automatically

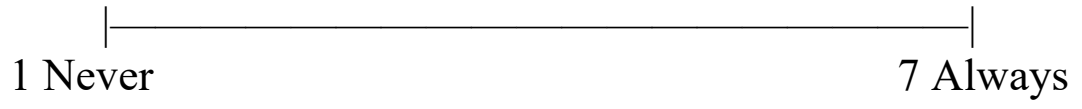

I am able to completely focus on my task without straining to pay attention

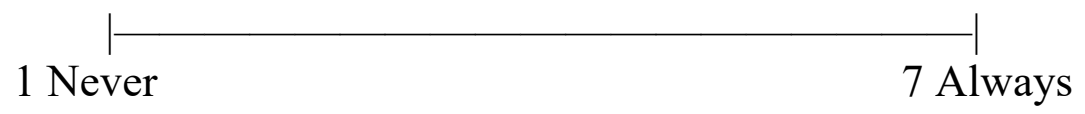

I feel like I don't have to force myself to keep fully engaged with an external task

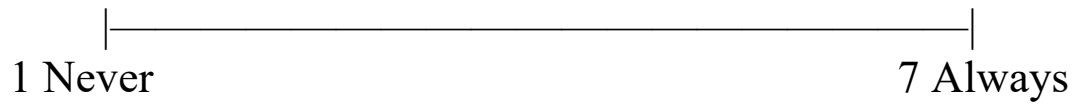

I seem to reach a deep level of focus almost effortlessly

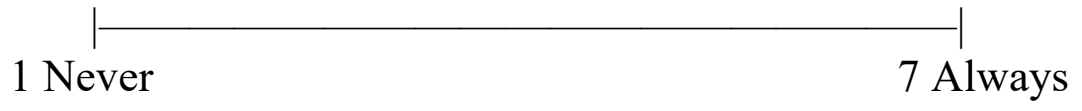

When performing an external task, I become completely engaged without having to work at it

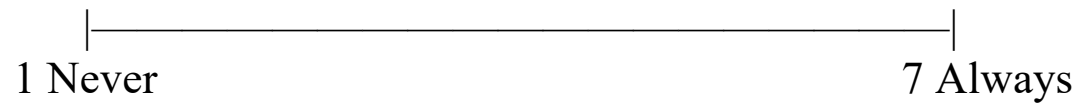

I get in the zone and don't have to force myself to concentrate on the task I am doing

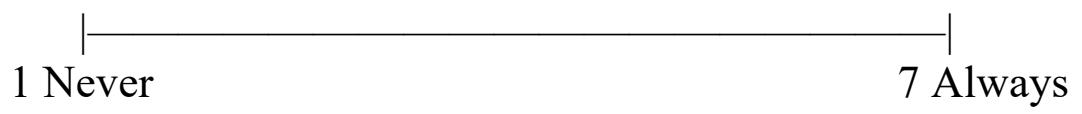


I can naturally and effortlessly sustain my full attention on a task

1 Never 7 Always

I can easily pay total attention to an external task for extended periods of time

1 Never 7 Always

